\title{
MECHANICAL ANALYSIS OF FEMORAL NECK FRACTURE FIXATION IN SYNTHETIC BONE
}

\author{
Anderson Freitas ${ }^{1}$, Bruna Alves Soares Azevedo ${ }^{1}$, Roberto Rodrigues de Souza ${ }^{1}$, Hélio Ismael da Costa ${ }^{1}$, \\ Rafael almeida Maciel ${ }^{1}$, Diogo Ranier de Macedo Souto ${ }^{1}$
}

\section{ABSTRACT}

Objective: To analyze statistically results obtained between biomechanical assays on fixation of femoral neck fracture type Pauwels III, on synthetic bone, using $7.5 \mathrm{~mm}$ non parallel cannulated screws and control group. Methods: Ten synthetic bones from a national brand were used. Test group: fixation of $70^{\circ}$ tilt femoral neck osteotomy was performed using three 7.5 $\mathrm{mm}$ non parallel cannulated screws. We analyzed the resistance of this fixation with $5 \mathrm{~mm}$ of displacement, and rotational deviation (phase 1) and with $10 \mathrm{~mm}$ offset (phase 2). Control group: the models were tested in their integrity until the femoral neck fracture occurred. Results: the values of the test group in phase
1 , in sample $1-5$ had a mean of $517 \mathrm{~N}$ and $\mathrm{SD}=96 \mathrm{~N}$. Rotational deviations showed a mean of $3.79^{\circ}$ e $\mathrm{SD}=2.03^{\circ}$. In phase 2 , mean was $649 \mathrm{~N}$ and $\mathrm{SD}=94 \mathrm{~N}$. The values of the maximum load in the control group were: $1544 \mathrm{~N}, 1110 \mathrm{~N}, 1359 \mathrm{~N}, 1194 \mathrm{~N}$, $1437 \mathrm{~N}$; respectively. Statistical analysis between the groups showed a statistically significant lower value in the test group. Conclusion: the analysis of mechanical resistance between the groups has determined statistically significant value for the test group. Level of Evidence III, Case-control Study.

Keywords: Femoral neck fractures. Fracture fixation, internal. Biomechanical phenomenas.

Citation: Freitas A, Azevedo BAS, Souza RR, Costa HI, Maciel RA, Souto DRM. Mechanical analysis of femoral neck fracture fixation in synthetic bone. Acta Ortop Bras. [online] 2014;22(3):155-8. Available from URL: http://www.scielo.br/aob.

\section{INTRODUCTION}

Among the diseases of the musculoskeletal system, hip fracture has high complication rates, regardless of surgical implants in orthopedics. Approximately 20-24\% of elder patients die in one year after a femoral neck fracture, pointing out the gravity of this injury. ${ }^{1}$ Costs regarding this type of injury in 60 year old patients are expected to reach 1.2 billion Dollars in 2025, and the number of hip fractures is estimated to grow in absolute numbers to 6.3 million per year up to $2050,80 \%$ of those patients being of the feminine gender. ${ }^{1}$

Pauwels' classification for femoral neck fracture was originally published in 1935 and it has been used by orthopedic surgeons since. This classification is based on the angle formed by the fracture tract. ${ }^{2}$ Bartonicek, in 2001, reviewed Pauwels classification and stipulated categories, considering the following as reproducible: Pauwels I, when the fracture angle is lower than $30^{\circ}$, Pauwels II, angle between 30 and $50^{\circ}$, and Pauwels III, when the angle is higher than $50^{\circ} .{ }^{3}$

The main methodology for the treatment of hip fractures is surgical, with a variability of methods of internal fixation and / or arthroplasty. ${ }^{4,5}$
Fixation with three parallel screws, although it is already a disseminated methodology in our midst, its use in femoral neck fracture requires scientific evidence to demonstrate its effectiveness on treatment of unstable fractures. ${ }^{5}$

Asnis ${ }^{6}$ described the fixation method of femoral neck fracture with cannulated screws in the configuration of an inverted triangle, one in the lower portion of the neck and two other screws in the anterior and posterior portions, respectively, in this fixation order. ${ }^{6,7}$

Nowakowski et al. ${ }^{2}$ in a biomechanical study assessing various synthetic methods for Pauwels type III fracture in synthetic bone, describes in one of his groups using non parallel cannulated screws obtaining, in this group, unfavorable results, when compared to other groups.

It is believed that the ideal implant for fractures of the femoral neck should follow some basic criteria, such as: 1) provide excellent results in simple or complex fractures of the femoral neck; 2) providing instrumental that allows the surgeon to perform excellent reduction; 3) allow compression of the fracture; 4) provide angular stability and prevent or minimize the shortening of the femoral neck; 5) allow minimally invasive incision;

All the authors declare that there is no potential conflict of interest referring to this article.

\section{Hospital Ortopédico e Medicina Especializada (HOME), Brasília, DF, Brazil.}

Work developed at Hip Service, Hospital Ortopédico e Medicina Especializada (HOME), Brasília, DF, Brazil.

Correspondence: Hospital Ortopédico e Medicina Especializada (HOME), SGAS Quadra 613 Conjunto C, 70200-730 Brasilia, DF, Brazil. andfreitas28@gmail.com 
6) provide excellent results even when the fracture does not present anatomic reduction.

Nonunion and displacement of fractures account for approximately $60 \%$ of the complications of femoral neck fractures. Most complications related to unstable fractures of the femoral neck are nonunion, bad consolidation, blood loss, and infection, and the most frequent among those is bad consolidation. ${ }^{8}$

The objective of this study is to perform a statistical analysis of the values obtained in mechanical tests on synthetic pre osteotomized bones, simulating a Pauwels type III fracture fixed with three non-parallel cannulated screws and control group.

\section{MATERIALS AND E METHODS}

Ten proximal synthetic femur bones from a national brand and same batch were used. They were divided into two groups, test and control. The test group consisted of five $200 \mathrm{~mm}$ synthetic bones with their integrity still intact, a fact that would allow anatomic reduction and optimization of compression on the fracture site after osteotomy. Three $7.5 \mathrm{~mm}$ cannulated screws were introduced not parallel. Initially a central upper screw positioned in the medial-lateral portion at a distance of $20 \mathrm{~mm}$ distal to the apex of the greater trochanter, perpendicular to the fracture line, were inserted. After inserting the screw top, there was the insertion of two parallel distal screws in the femoral head, at the height of the apex of the lesser trochanter, on the medial-lateral portion of the femur. The first screws inserted were the parallel ones, then the posterior screw with cortical support, and the second, parallel to that, at the most anterior portion of the femoral neck. All screws are positioned $5 \mathrm{~mm}$ from the articular surface. For correct positioning of the fixation, fluoroscopic control in AP and lateral during each step of the procedure was performed. After this step, the screws were removed, and osteotomy was performed at $70^{\circ}$ in relation to the horizontal axis with a prefabricated template so that there were angular differences between the tested bones, simulating a Pauwels type III fracture. All models were X-rayed after fixation for assessment of the reduction and placement of screws. (Figures 1A, B and 2A) The analysis of the mechanical assay of the test group was divided into two phases: the fixation strength within $5 \mathrm{~mm}$ displacement (Figure 2B), the fixation strength at $10 \mathrm{~mm}$ displacement (Step 2 - Figure 2C) and evaluation of the rotational deviation (Phase 1 Figure 3-A, $B)$. The control group, which was formed by five synthetic models with $125 \mathrm{~mm}$ long bones, was tested intact until the fracture of the femoral neck. (Figure 4A, B). Determined in this way, a value in Newton ( $N$ ) at the exact time of occurrence of fracture, which in the authors's view is the minimum load that should be supported by the synthesis method to allow early mobility and ambulation with load, without loss of reduction or synthesis failure.

Both groups were tested on the test machine MTS (Materials Testing System) 810 - FlexTest 40 (USA) with a capacity of $100 \mathrm{kN}$ at an application load rate of $200 \mathrm{~mm} / \mathrm{min}$. A load cell capacity of $10 \mathrm{kN}$ calibrated and tested was used in the assay. (Figure 5)

The statistical method used was Mann-Whitney's ${ }^{9}$ for comparison of the maximum force $(\mathrm{N})$ between the control group and test group. The nonparametric method was used since the

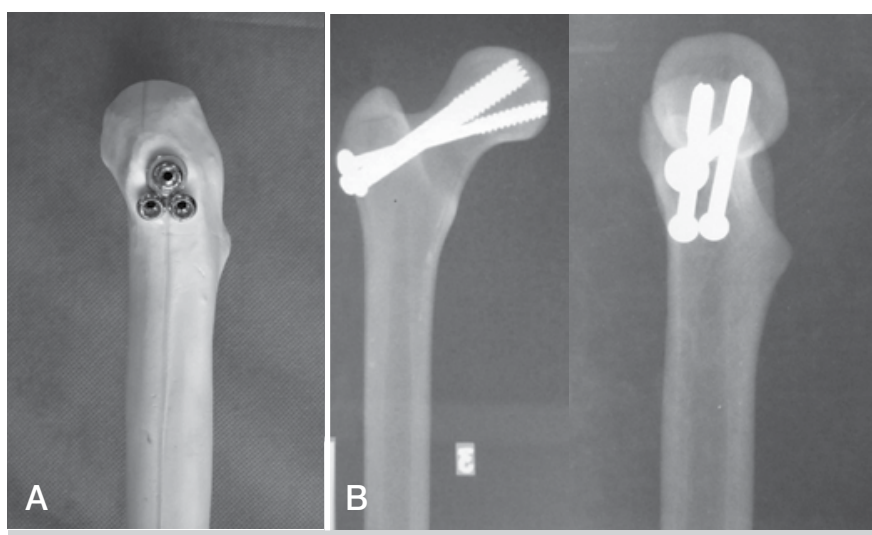

Figure 1. A) Image of the synthetic bone fixed with three $7.5 \mathrm{~mm}$ cannulated screws. B) X-ray of synthetic models fixed for assessment of fair positioning of synthesis.
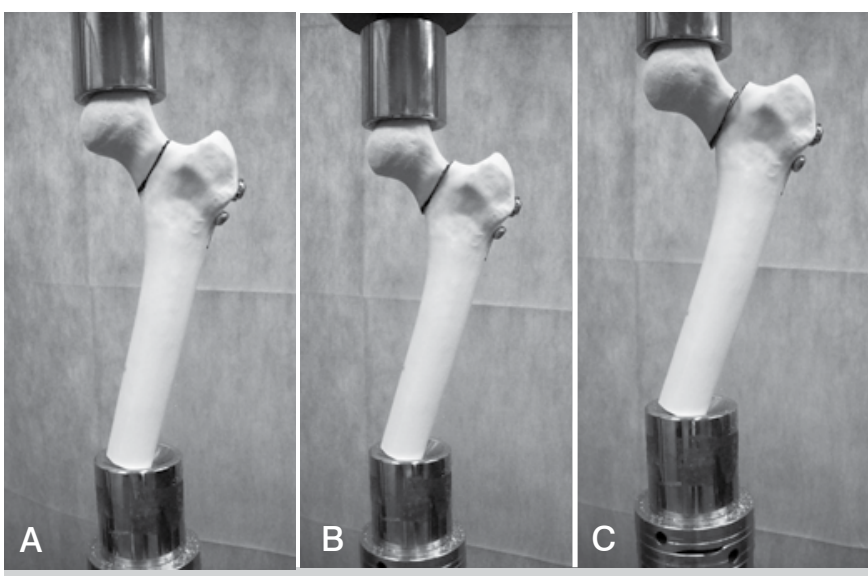

Figure 2. A) Image of the synthetic bone fixed in the machine, at the pre-test. B) Image of the bone model during the assay with $5 \mathrm{~mm}$ displacement (phase 1). C) Image of the bone model during the assay with $10 \mathrm{~mm}$ displacement (phase 2).
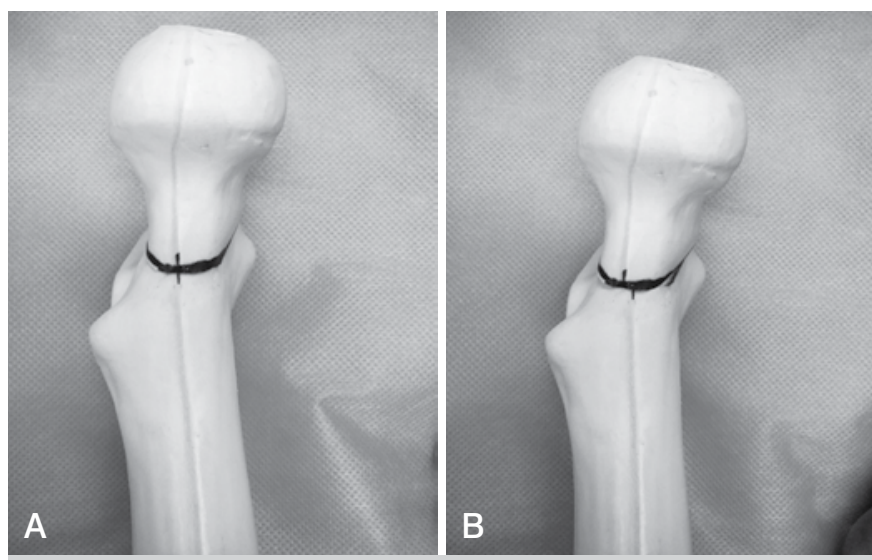

Figure 3. A) Mark to assess the rotational deviation pre-test. B) Image of the misaligned mark after one phase of the assay on the test group

maximum force is not normally distributed (Gaussian distribution), due to the small sample size analyzed in each group.

The criterion for determining statistical significance was set at $5 \%$. Statistical analysis was performed with the SAS 6:11 software (SAS Institute, Inc., Cary, North Carolina). 

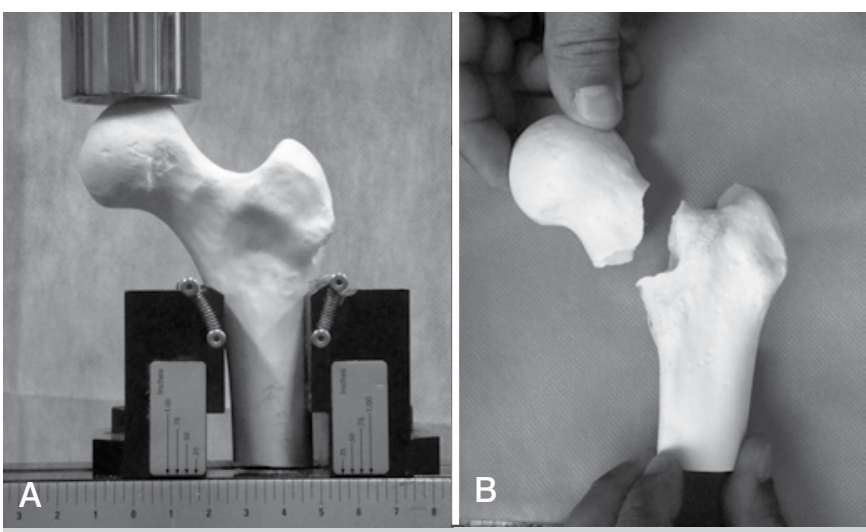

Figure 4. A) Image of the synthetic model of the control group in the assay machine at pre- test. B) Image of the synthetic model of the control group at post-test.

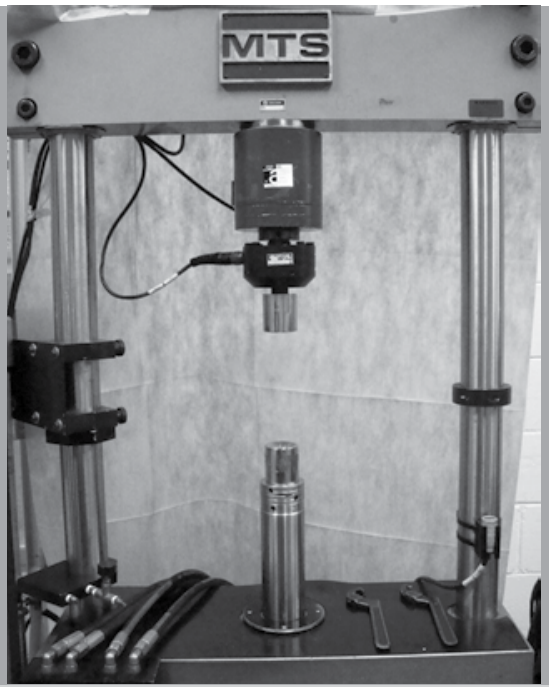

Figure 5. Machine used at the assays.

\section{RESULTS}

Test Group: The value of load in Newtons ( $\mathrm{N}$ ) applied until the fracture displacement in $5 \mathrm{~mm}$ (Phase 1) was 512N, 400N, 660N, $468 \mathrm{~N}$, and $543 \mathrm{~N}$, respectively, for samples 1 to 5 . These values presented a mean value of $517 \mathrm{~N}$ and a standard deviation of $96 \mathrm{~N}$. The amount of load to the displacement of fracture by $10 \mathrm{~mm}$ (Phase 2) in Newtons (N) applied to five samples were, respectively, $640 \mathrm{~N}, 555 \mathrm{~N}, 801 \mathrm{~N}, 593 \mathrm{~N}$, and $655 \mathrm{~N}$. The mean value was $649 \mathrm{~N}$ and standard deviation $94 \mathrm{~N}$. The values of the rotational deviation in degrees measured at the end of the first phase, were, respectively: $7.16^{\circ}, 3.60^{\circ}, 3.27^{\circ}, 3.29^{\circ}$, and $1.64^{\circ}$, presenting mean value $3.79^{\circ}$ and standard deviation $2.03^{\circ}$. (Table 1 and Figure 6 ) Control group: The load values in Newtons $(\mathrm{N})$ applied until frac-

Table 1. Values of essays on models of the test group on phases 1 and 2.

\begin{tabular}{c|c|c|c}
\hline Sample & $\begin{array}{c}\text { Load with } 5 \mathrm{~mm} \\
\text { displacement(N) }\end{array}$ & $\begin{array}{c}\text { Load with } 5 \mathrm{~mm} \\
\text { displacement(N) }\end{array}$ & $\begin{array}{c}\text { Rotation } \\
\text { (degrees) }\end{array}$ \\
\hline 1 & 512 & 640 & 7.16 \\
\hline 2 & 400 & 555 & 3.60 \\
\hline 3 & 660 & 801 & 3.27 \\
\hline 4 & 468 & 593 & 3.29 \\
\hline 5 & 543 & 655 & 1.64 \\
\hline Mean & 517 & 649 & 3.79 \\
\hline St. Deviation & 96 & 94 & 2.03 \\
\hline
\end{tabular}

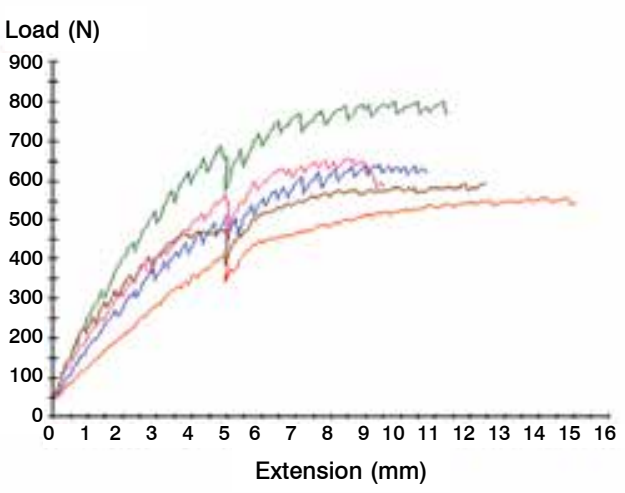

Figure 6. Curve strength versus displacement on the assays of models of the test group.

ture of the femoral neck in the control group were in samples 1-5: 1544N, $1110 \mathrm{~N}, 1359 \mathrm{~N}, 1194 \mathrm{~N}$ and $1437 \mathrm{~N}$, respectively, presenting a mean value of $1329 \mathrm{~N}$ and standard deviation of $177 \mathrm{~N}$ (Table 2 and Figure 7) The Mann-Whitney ${ }^{9}$ test revealed that the test group showed maximum force at $10 \mathrm{~mm}$ displacement significantly lower than the control group $(p=0.009)$. (Figure 8).

Table 2. Values of essays on models of the control group.

\begin{tabular}{c|c}
\hline Sample & $\begin{array}{c}\text { Control group } \\
\text { Maximum Load (N) }\end{array}$ \\
\hline 1 & 1544 \\
\hline 2 & 1110 \\
\hline 3 & 1359 \\
\hline 4 & 1194 \\
\hline 5 & 1437 \\
\hline Mean & 1329 \\
\hline St. Deviation & 177
\end{tabular}

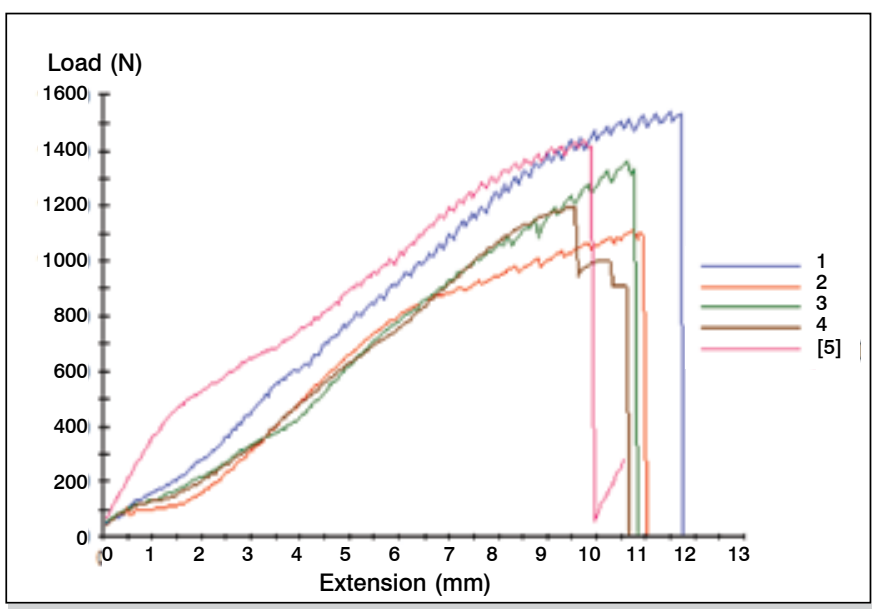

Figure 7. Curve strength versus displacement for the control group.

\section{DISCUSSION}

The fixation of femoral neck fractures with multiple screws has a high rate of complications when analyzing femoral neck shortening, which causes poor postoperative functional level and patient dissatisfaction. ${ }^{8}$ Alves describes the uncertainty of the changes caused in the abductor moment that affects directly shortening of the cervix. He also reports that the greater the shortening, the greater the failure and decline, a reason why this occurs. ${ }^{10}$ 


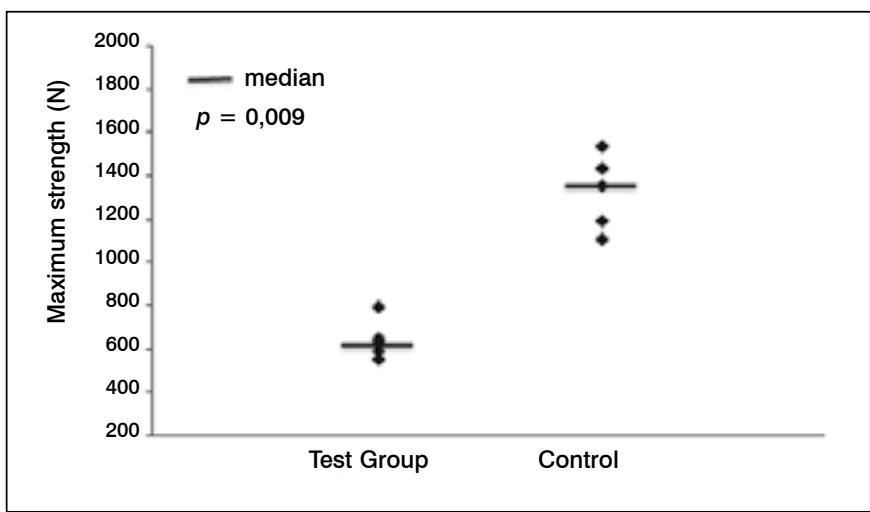

Figure 8. Maximum strength in $10 \mathrm{~mm}$ displacement according to test group and control group

Patients submitted to surgical treatment of femoral neck fracture, despite new evidence, show high mortality rate $(20 \%)$ and a rate of revision surgeries of about $35 \%$. In view of this, and since there is still the need to develop new and better implants, with better quality and new techniques, that provide the patient with femoral neck fracture better results. Hip arthroplasty is the most accepted method for treatment of femoral neck fracture by $47 \%$ of hip surgeons, instead of internal fixation, for elderly patients. However, in young patients we should always prioritize osteosynthesis, even in displaced and unstable fractures. Anatomical reduction is considered by half the surgeons as the most crucial point to a good outcome of the surgical treatment for this disease, independently of the fixation metho used. ${ }^{3}$

Frandsen et al. and Zlowodzki et al. determined that, however the classification used, and due to the low reproducibility showed between them, it is important to determine the instability degree of the fracture, which depends on communication between the fracture and the fracture angle, in order to determine the best treatment method. ${ }^{11-12}$

During the last decade, with the advent of fixed angles instru- mental, there was an improvement in the results of treatment of metaphyseal, diaphyseal and some periarticular fractures. In contrast, fractures of the femoral neck are not part of this evolution regarding internal fixation. ${ }^{1}$ The adverse outcomes are associated with advanced age, cognitive impairment, social inactivity and bone quality. ${ }^{10}$

In a recent study, from $89 \%$ to $69 \%$ of surgeons believe that the shortening caused by femoral neck fracture reduces the abductor function and functional loss of the patient, respectively. ${ }^{12}$

The use of non-parallel cannulated screws emerged in order to annul the shear strength existing on unstable angular fractures, described as the main reason for complications in these fractures treated with cannulated parallel screws or sliding screw, however Parker, in 1991, already described that this method also evolved with complications, ${ }^{13}$ confirming the results shown in this article.

The choice of synthetic bone was determined to provide comparable biomechanical properties between the groups, eliminating variables. Thus, we removed possible changes inherent to human bones, which would make the evaluation of the fixation methodology arguable, due to their non-uniform characteristics (bone density, diameter and length).

\section{CONCLUSION}

There is statistical significant difference between the control group, synthetic bones without synthesis, and the test group, synthetic bones with Pauwels type III fractures fixed with cannulated non parallel screws $(p=0.009)$. The fixation of Pauwels type III fracture with cannulated not parallel screws in synthetic bones allowed a rotational deviation of $3.79^{\circ}$, on average.

\section{ACKNOWLEDGEMENTS}

The authors wish to thank Prof. Ana Patrícia Paula, Master of Science supervisor of Fundação de Ensino e Pesquisa em Ciência da Saúde (Fepecs), for unconditional support.

\section{REFERENCES}

1. Rueger J, Moore C. Shortening of the femoral neck following peritrochanteric fracture. Bone Joint Sci. 2011; 2(5). Disponível em: http://www.smith-nephew.com/global/assets/ pdf/temp/71181925_trigen_intertan_short_of_fem_neck_wp_web_\%28copy-1\%29.pd

2. Pauwels F. Der schenkelhalsbruch em mechanisches problem : Grundlagen des Heilungsvorganges Prognose und kausale Therapie. Stuttgart: Ferdinand Enke Verlag, 1935.

3. Bartonícek J. 'classification of femoral neck fractures: correct interpretation of the original. J Orthop Trauma. 2001;15(5):358-60.

4. Zlowodzki M, Brink O, Switzer J, Wingerter S, Woodall J Jr, Petrisor BA, et al. The effect of shortening and varus collapse of the femoral neck on function after fixation of intracapsular fracture of the hip: a multi-centre cohort study. J Bone Joint Surg Br. 2008;90(11):1487-94

5. Mattsson $\mathrm{P}$, Larsson S. Stability of internally fixed femoral neck fractures augmented with resorbable cement. A prospective randomized study using radiostereometry. Scand J Surg. 2003;92(3):215-9.

6. Asnis, Stanley E., and Leslie Wanek-Sgaglione. "Intracapsular fractures of the femoral neck. Results of cannulated screw fixation." The Journal of Bone \& Joint Surgery 76.12 (1994): 1793-1803.

7. Gurusamy K, Parker MJ, Rowlands TK. The complications of displaced intracapsular fractures of the hip: the effect of screw positioning and angulation on fracture healing. J Bone Joint Surg Br. 2005:87(5):632-4.

8. Parker MJ, Blundell C. Choice of implant for internal fixation of femoral neck fractures. Meta-analysis of 25 randomised trials including 4,925 patients. Acta Orthop Scand. 1998;69(2):138-43.

9. Hollander M, Wolfe DA. Nonparametric statistical methods. 2nd ed. New York: John Wiley \& Sons; 1999.

10. Alves T, Neal JW, Weinhold PS, Dahners LE. Biomechanical comparison of 3 possible fixation strategies to resist femoral neck shortening after fracture. Orthopedics. 2010;33(4). doi: 10.3928/01477447-20100225-07. Epub 2010 Apr 16

11. Frandsen PA, Andersen E, Madsen F, Skjødt T. Garden's classification of femoral neck fractures. An assessment of inter-observer variation. J Bone Joint Surg Br. 1988;70(4):588-90.

12. Zlowodzki M, Brink O, Switzer J, Wingerter S, Woodall J Jr, Petrisor BA, et al. The effect of shortening and varus collapse of the femoral neck on function after fixation of intracapsular fracture of the hip: a multi-centre cohort study. J Bone Joint Surg Br. 2008;90(11):1487-94.

13. Parker MJ, Porter KM, Eastwood DM, Schembi Wismayer M, Bernard AA. Intracapsular fractures of the neck of femur. Parallel or crossed garden screws? J Bone Joint Surg Br. 1991;73(5):826-7. 